\section{A paisagem linguística de um campus universitário fronteiriço: língua e poder em perspectiva}

Linguistic landscape of a crossborder university campus: language and power in perspective

Isis Ribeiro BERGER (UNIOESTE) isisrberger@gmail.com

Michelle LECHETA (UNIOESTE) michelle.lecheta@gmail.com

Recebido em: 19 de jan. de 2019. Aceito em: 22 de maio de 2019.
BERGER, Isis Ribeiro; LECHETA,

Michelle. A paisagem linguística de um campus universitário fronteiriço: língua e poder em perspectiva. Entrepalavras, Fortaleza, v. 9, n. 2, p. 396-414, maio-ago/2019.

Resumo: $O$ presente artigo se propõe a lançar o olhar às intervenções linguísticas explicitadas nas paredes de um campus universitário em Foz do Iguaçu (PR), de modo a compreender de que forma a percepção dessa Paisagem Linguística pode ser uma ferramenta que revele, para além das demandas estudantis impressas nas paredes, questões políticas e socioculturais, inerentes não somente à comunidade acadêmica, mas à sociedade como um todo. Baseamonos nos conceitos de Paisagem Linguística (LANDRY; BOURHIS, 1997; SHOHAMY, 2006; SPOLSKY, 2009), buscando expandilos ao trazer ao diálogo as formulações da Geografia da Visibilidade (GOMES, 2013) acerca da disposição dos elementos na paisagem. Partimos ainda da análise das relações de poder (FOUCAULT, 1979; 1995; 2010; 2014) no sentido de destacar o caráter de resistência dessas intervenções, ao se fazerem presentes em espaços em que se "normatiza" a higienização. Utilizamos, para tanto, a tomada e análise de fotografias dos muros e paredes dos espaços de circulação pública do campus universitário. A análise desses elementos, a partir das motivações de sua produção, sugeriu que a Paisagem Linguística pode se caracterizar como um reflexo da necessidade de representação e visibilidade de determinados grupos.

Palavras-chave: Paisagem linguística. Visibilidade. Poder. 
Abstract: The present article proposes to set an eye to the linguistic interventions displayed on the walls of a university campus in Foz do Iguaçu (PR), in order to comprehend how the perception of this Linguistic Landscape can be used as a tool which reveals not only student demands printed on the walls, but also political and sociocultural issues related to the society as a whole. We are based on the concepts of Linguistic Landscape (LANDRY; BOURHIS, 1997; SHOHAMY, 2006; SPOLSKY, 2009), seeking to expand them as we bring to the dialogue the formulations of the Visibility Geography (GOMES, 2013), concerning the position of elements on the landscape. We are also based on the power relations analysis (FOUCAULT, 1979; 1995; 2010; 2014) in order to highlight the resistance characteristic of these interventions when they are presented in spaces normalized by the cleanliness. For this purpose, we used the photograph takes followed by the analysis of walls that belong to the public circulation spaces of the campus. The analysis of these elements, focused on their production motivations, suggested the Linguistic Landscape may be characterized as a reflection of the need for representation and visibility of certain groups.

Keywords: Linguistic landscape. Visibility. Power.

\section{Introdução}

Este estudo, alicerçado no campo da Paisagem Linguística, tematiza os usos das línguas no espaço público de uma instituição de ensino superior, localizada em Foz do Iguaçu-PR, como estratégia de poder e resistência. O campo da Paisagem Linguística (doravante PL) visa analisar a forma como as línguas se fazem presentes nos espaços de convívio social, sejam públicos ou privados, com vistas a depreender como se manifestam as relações de poder entre elas (ecologia das línguas) em espaços de visibilidade, bem como identificar políticas linguísticas (implícitas ou explícitas) que culminam na exposição ou marginalização de línguas (e mensagens nessas línguas) em dado território.

No que se refere às línguas nos espaços públicos, trata-se da presença de itens linguísticos encontrados em ambientes, como ruas, centros comerciais, hospitais, instituições de ensino ou quaisquer outros espaços públicos, transmitindo algum tipo de mensagem nos espaços de visibilidade. Consoante Landry e Bourhis (1997), pressupomos que, ao revelar a invisibilização de determinadas línguas ou a superexposição de outras na paisagem pública urbana, a PL possibilita identificar o status e poder de determinadas línguas e grupos sociais, bem como territórios linguísticos ${ }^{1}$. Nesse sentido, Shohamy afirma que

\footnotetext{
${ }^{1}$ Entendemos como territórios linguísticos a demarcação de espaços sociais por determinados grupos, por meio dos usos de suas línguas como traços diferenciais entre grupos étnicos e sociais. Trata-se de uma extensão do conceito de território como demarcação de espaços físicos ou de interação social por meio de elementos simbólicos e culturais, delimitando fronteiras (BERGER, 2015; 2016).
} 
V. 9 (2)

$396-414$

maio-ago

2019

[...] o espaço público serve tanto como ferramenta nas mãos de diferentes grupos para a transmissão de mensagens quanto ao lugar de diferentes línguas em instâncias políticas e geográficas, quanto para influenciar e criar realidades linguísticas. (SHOHAMY, 2006, p. 1112)

Ainda nesse sentido, Spolsky (2009, p. 70)3, ao tratar das questões inerentes à origem dos sinais linguísticos que compõem determinada paisagem, afirma que "a grande maioria dos estudos de sinais são baseados na observação, contagem e tomadas fotográficas dos sinais já expostos, sem olhar para o processo pelo qual determinado sinal foi produzido". Desse modo, nesse trabalho, direcionamos nosso olhar não só para a percepção e a análise da diversidade de línguas que se faz presente no espaço social investigado, mas também para as possíveis motivações de produção dos sinais verbais, visando demonstrar que esse campo de investigação pode se caracterizar como ferramenta através da qual questões sociais, políticas e econômicas se revelam. Para tanto, por meio da análise de diversos elementos constitutivos do espaço público, não só concernente à presença/ausência de línguas em dada paisagem, mas também no que tange à percepção do conteúdo linguísticosimbólico expresso nos múltiplos espaços de convívio social citadino, o objetivo aqui proposto é compreender as diferentes manifestações de poder e resistência que são explicitados nas mensagens.

De acordo com Ben-Rafael et al (2006), a análise integral dos elementos linguísticos dispostos em determinada paisagem "traça um campo que justifica um estudo sistemático, podendo assim constituir uma maneira interessante de revelar realidades sociais". (BEN-RAFAEL et al, 2006, p.94). Entendemos, portanto, que a PL pode ser lida como expressão de subjetividades sociais ao tomarmos como objeto de análise as intervenções linguísticas dos muros e paredes que compõem o espaço público de circulação do campus de uma universidade no município fronteiriço de Foz do Iguaçu - PR. A instituição em foco tem em seu cerne a especificidade de se dedicar à valorização da diversidade cultural, almejando maior integração entre os

\footnotetext{
2 "[...] the public space serves as a tool in the hands of different groups for the transmission of messages as to the place of different languages in the geographical and political entities and for influencing and creating de facto language realities" (SHOHAMY, 2006, p.111).

3 "The vast majority of studies of signs are based on observation, counting, and (nowadays thanks to digital cameras) photographing actual finished signs, and not looking at the process by which that particular sign was produced" (SPOLSKY, 2009, p.70).
}

4 "[...] outline a field that may justify a systematic study as it may constitute an interesting way of uncovering social realities" (BEN-RAFAEL, 2006, p.9). 
países latino-americanos, em uma concepção de América Latina una, mas diversa. Nesse sentido, entendemos que esse espaço se configura como ambiente sociolinguístico diverso em que múltiplas realidades linguísticas e demandas sociais e políticas se encontram.

Partindo das tomadas de fotografia do espaço público indicado, procedimento primordial das investigações no campo da PL, defrontamonos com inúmeras intervenções linguísticas que trazem em seu conteúdo manifestos reivindicando desde necessidades estudantis, como também clamores por respeito à diversidade e por valorização de identidades, o que coloca em tensão o ideal constitutivo de integração da universidade.

Diante desse contexto, o presente trabalho foi desenvolvido em uma perspectiva interdisciplinar (RAYNAUT, 2011) tendo como eixo diferentes estudos em PL (LANDRY; BOURHIS, 1997, SHOHAMY, 2006; 2009, SPOLSKY, 2009), na interface com o olhar geográfico-espacial de Gomes (2013), que, ao enunciar determinadas condições de visibilidade, permite-nos ressignificar nosso objeto de análise tendo como princípio uma proposta de geografia da visibilidade. Dialogamos, ainda, com as elaborações de Foucault (1979, 1995, 2010, 2014) acerca do poder, buscando compreender de que forma as intervenções linguísticas nos muros e paredes do campus podem se revelar uma arena de resistência contra a assimilação de normas que regem o que pode e o que não pode compor as paisagens do espaço público.

De modo a atingir o objetivo proposto, iniciamos o texto com uma exposição sobre o campo da Paisagem Linguística e realizando um breve panorama dos estudos que voltam o olhar para a composição linguística dos espaços urbanos. Em seguida, discorremos sobre os procedimentos metodológicos adotados para a pesquisa, contextualizando ainda o ambiente sociolinguístico escolhido, de modo a apresentar suas características e especificidades. Na sequência, procedemos com a apresentação e análise da PL em questão, por meio de fotografias que englobam questões de diversidade linguística, de poder, de gênero e de cor, refletindo sobre as relações de poder que subjazem a essas intervenções.

\section{Os estudos em paisagem linguística: aspectos teóricos e metodológicos}

A observação dos elementos linguísticos, sejam eles dispostos em placas de trânsito, propagandas em outdoors, letreiros dos estabelecimentos comerciais, intervenções artísticas em muros e paredes, totens informativos entre outras formas de apresentação das línguas no meio público e privado, constituem o objeto de análise do 
V. 9 (2)

$396-414$ maio-ago 2019 campo de estudos em Paisagem Linguística. Trata-se de um campo que emerge a partir da Sociolinguística e Política Linguística visando compreender as escolhas linguísticas em sinais públicos localizados em ambientes urbanos mono/bi/multilíngues, em sua relação com a sociedade (SPOLSKY, 2009).

A primeira definição para o conceito de PL foi proposta por Landry e Bourhis (1997) e referenciava a PLà "visibilidade e proeminência das línguas em sinais públicos e comerciais em um dado território ou região" (LANDRY; BOURHIS, 1997, p. 235). Em sua concepção, a PL serviria a duas funções distintas: a informativa e a simbólica. A função informativa tangencia o delineamento de uma fronteira linguística, tratando-se assim de uma marcação de território geográfico ao qual pertence determinada comunidade linguística. A função simbólica, por sua vez, dá-se no âmbito das relações entre visibilidade e invisibilidade de representação dessas comunidades na paisagem, demonstrando lugares de status e poder de determinados grupos dominantes. Desse modo, para os pesquisadores do campo, os estudos em PL contribuem para revelar a manutenção da vitalidade de comunidades linguísticas, dada a partir dos graus de presença de determinadas línguas nos sinais urbanos, demostrando assim a representatividade desse grupo.

Complementarmente, Gorter (2006) reúne uma série de artigos que analisam o campo sob diferentes óticas, desde estudos empíricos em diferentes localidades como Israel, Japão, Tailândia, Países Baixos e Espanha, a análises sociais que tangem a função simbólica trazida anteriormente por Landry e Bouhis (op. cit). Conforme destaca o autor, o conceito de PL tem sido utilizado de formas distintas, tanto no sentido mais abrangente no que se refere à análise de como determinada língua se apresenta em dado local, quanto no sentido da observação da presença e do uso de diversas línguas em um espaço geográfico mais amplo.

Já Shohamy (2009) trata de expandir as possibilidades de análise da PL, primeiramente ao apresentá-la como campo interdisciplinar ao tangenciar diversos campos do saber como Geografia, Sociologia, Educação, Economia, Planejamento urbano, o que faz atrair, conforme argumenta, pesquisadores que se mostram dispostos a compreender significados mais profundos performados nos espaços. Em seguida, a autora constata que a rápida emergência dos espaços virtuais e da internet introduz uma nova possibilidade de percepção da PL sem que

5 "Linguistic landscape refers to the visibility and salience of languages on public and commercial signs in a given territory or region" (LANDRY; BOURHIS, 1997, p. 23). 
seja necessária a presença propriamente física do observador. Dada essa possibilidade de expansão do campo de análise em PL, concordamos com Shohamy sobre a necessidade de levantar importantes questões como:

Que tipo de realidade a PL cria e forma? O que motiva as pessoas a exibir a linguagem? Como as pessoas avaliam a PL? Que mensagens estão sendo entregues aos passantes? Que tipo de linguagem está sendo criada no espaço público? De que forma as imagens e demais tipos de representação interagem entre si? (...) E finalmente, o que pode acrescentar o estudo de PL em suas muitas perspectivas para nossa compreensão de língua, sociedade e as pessoas? (SHOHAMY, 2009, p. $2^{6}$ ).

Além dos estudos em nível internacional, há uma crescente produção no campo da PL em meio a pesquisadores que têm contribuído com esses estudos em diferentes contextos sociolinguísticos no Brasil. Nesse sentido, destacamos também, no contexto de Foz do Iguaçu PR, a pesquisa de Silva; Pires-Santos e Jung (2016), que analisa de que maneira a PL urbana desse município, situado na tríplice fronteira entre Argentina, Brasil e Paraguai, representa o multilinguismo no espaço público urbano e, ainda, quais políticas linguísticas são possíveis de serem identificadas nessa representação. Segundo as pesquisadoras, a análise da PL nesse espaço transfronteiriço viabiliza a apreensão de assimetrias quanto à veiculação das línguas. Em especial, da língua guarani, quase invisível perante a presença eminente da língua portuguesa, língua oficial nacional do Estado brasileiro, e da língua inglesa, como língua "translocal" que representa o fluxo turístico da região e que ao mesmo tempo, dada sua preponderância, simboliza o status econômico e político dessa língua hipercentral globalizante.

Ainda, nesse mesmo contexto transfronteiriço, Berger e Elsenbach (2017) investigaram como se dá a disposição das diferentes línguas que coexistem nesse espaço, utilizando-se de aporte teórico interdisciplinar de análise, convergindo saberes advindos dos campos da Geografia, da Política Linguística e da Sociolinguística. A pesquisa teve como propósito analisar as condições para a visibilidade das diversas línguas em uso no município.

\footnotetext{
6 "What kind of reality does LL create and shape? What motivates people to display language? How do people value LL? What messages are being delivered to passers-by? Which types of language(s) are being created in the public space? How do images and all other representations interact? And finally, what does the study of LL in its many perspectives add to our understanding of language, society and people?" (SHOHAMY, 2009, p.2)
} 
V. 9 (2)

$396-414$

Destacamos, ainda, no contexto de Juiz de Fora - MG, a contribuição de Soares (2018), ao defender como a superdiversidade linguística está presente na PL da cidade, a partir da análise dos ' grafismos urbanos', englobados pelas pichações e grafites. Sua pesquisa aponta, a partir da tomada de fotografias e da realização de pesquisa etnográfica, de que maneira essas intervenções constituem a PL da cidade e sua representação dentro de um contexto linguístico 'superdiverso'7.

Verifica-se, portanto, que é crescente a preocupação com a análise de como as línguas são veiculadas no espaço urbano, motivando assim, investigações que se acomodam tanto sob a perspectiva do plano informativo quanto a do plano simbólico, indo desde a presença/ ausência das línguas na paisagem até a circunscrição do debate às questões sociológicas inerentes a essas presenças, ausências e formas de expressão linguística.

Ressaltamos que o presente estudo se inscreve justamente na análise das formas de expressão linguística performadas a partir das intervenções em um espaço público universitário na cidade de Foz do Iguaçu e das maneiras como essas intervenções se estabelecem no plano simbólico das relações de propriedade, possibilidade e poder.

No que tange à metodologia empregada nos estudos em PL, de acordo com Gorter (2006), a PL se constitui por um estudo ainda em recente desenvolvimento, o que permite que, a cada nova pesquisa, novos passos metodológicos sejam calcados. Primordialmente, o fundamento da pesquisa em PL se dá pela delimitação de uma região geográfica que se deseja analisar e pela tomada de fotografia da PL que ali se insere. Das imagens extraídas desse cenário, faz-se a delimitação da amostragem, que pode se dar pela escolha da aparição ou ausência de determinadas línguas ou códigos linguísticos (ao pensarmos os grafites e demais intervenções semióticas). Em seguida, conforme adverte o autor, é necessária a "categorização desses sinais", distinguindo os sinais oficiais (top-down signs) dos não oficiais (bottom-up signs), sendo esses últimos o objeto de análise dessa pesquisa. Após a sistematização e codificação da amostra, as fotografias poderão ser quantificadas e analisadas.

De maneira a ampliar as possibilidades metodológicas dos estudos em PL, Malinowski (2009) propõe, para além da coleta e análise quantitativa da amostragem fotográfica, a consideração da questão da "autoria" dos elementos da PL, levantando a reflexão sobre a motivação

7 Entendemos o conceito de superdiversidade como "a diversidade dentro da diversidade" conforme aponta Blommaert apud Soares (2016, p. 210). 
do sujeito agente sobre a paisagem, atendo-se à significância simbólica daquela intervenção linguística. Desse modo, faz-se necessário conhecer o ambiente de exposição dessas intervenções, de forma a possibilitar a compreensão de sua existência e conteúdo.

\section{O ambiente sociolinguístico e procedimentos adotados}

Apresentamos agora o ambiente sociolinguístico onde se procedeu a investigação que culminou nesse texto, bem como os procedimentos adotados para fins do objetivo traçado. Conforme apresentado, a Instituição de Ensino Superior (doravante IES), em que se procedeu a investigação configura-se como ambiente sociolinguístico peculiar em que muitas línguas e vozes estão em situação de contato, encontro e desencontro. Um dos pilares institucionais é o bilinguismo, tendo português e espanhol como línguas centrais. Para além dessas, porém, há ainda uma pluralidade de línguas como o crioulo haitiano e línguas indígenas como guarani, quéchua e aymará, visto a procedência geográfica bastante diversa dos estudantes ali inseridos. A presença de um grande número de professores estrangeiros - hispano-falantes, além dos brasileiros, também desenha o cenário rotineiro de aulas ministradas em português e espanhol.

A partir desse contexto e da constatação da diversificada e demasiada quantidade de intervenções linguísticas nos espaços públicos da universidade, percebemos a relevância de análise dessa PL que tem em sua constituição frases de protesto, indagações filosóficas, poemas, grafites, pinturas e impressões em diversos idiomas, dado o caráter diverso da comunidade acadêmica que compõe a instituição.

A pesquisa de campo foi desenvolvida no primeiro semestre de 2018, em que se procedeu aos registros fotográficos e observação em campo. Segundo Gomes (2013, p. 6), "determinadas condições contribuem diretamente para que algumas imagens sejam mais notadas, sejam privilegiadas em detrimento de outras.". Assim, de modo a conferir atenção aos registros encontrados nas paredes e muros desse espaço, inicialmente partimos de uma observação geral e, na sequência buscamos realizar a maior quantidade de registros possíveis de modo a realizar uma seleção posterior. A observação foi importante no sentido de que, também consoante Gomes (2013, p.31-32), "o olhar percorre e não se fixa. Por isso, ver algo significa extraí-lo dessa homogeneidade indistinta do olhar, significa conferir atenção, tratar esse algo como especial". 
V. 9 (2)

$396-414$

maio-ago 2019

Registramos um total de 53 fotografias da paisagem linguística da instituição, tendo como critério a tomada das imagens que eram constituídas de mensagem escrita, independentemente do idioma escolhido pelo autor ou autora da intervenção. Ainda como parte da contextualização do ambiente sociolinguístico, acessamos o Sistema Eletrônico do Serviço de Informação ao Cidadão (e-SIC) do governo federal, a fim de obter informações específicas acerca do corpo discente da universidade, que, via Pró-Reitoria de Assuntos Estudantis (PRAE), forneceu os dados requeridos ao e-SIC, atendendo assim nossa solicitação. Conforme adverte Gil (2011):

Todas as sociedades modernas dispõem de grande quantidade de dados estatísticos referentes às características de seus membros. Tais dados são geralmente coletados e armazenados para servir aos interesses de organizações, sobretudo da Administração Pública. Todavia, podem ser muito úteis para a pesquisa social. (GIL, 2011, p. 148)

Para tanto, nossos questionamentos foram o número de estudantes brasileiros e estrangeiros da instituição; o número de estudantes de gênero feminino e masculino; a quantidade de estudantes cotistas; a quantidade de estudantes que recebem auxílio estudantil institucional; a quantidade de estudantes autodeclarados negros e pardos e por fim, a quantidade de estudantes que se utilizam de nome social. Consideramos que essas questões nos possibilitariam uma melhor compreensão da realidade estudada.

De acordo com os dados informados, verificamos que há um número expressivo de estudantes estrangeiros, preponderantemente hispano-falantes, embora os estudantes brasileiros sejam a maioria. Os números também apontam para a predominância de estudantes autodeclarados brancos, perfazendo o total de $67 \%$ dos estudantes da instituição, em contraponto aos 33\% de estudantes declarados pretos e pardos. Diante dos dados recebidos, sistematizamos o gráfico a seguir contendo o número exato de estudantes que compõe o corpo discente em diferentes categorias. 
Gráfico 1 Dados da IES

\section{Estudantes da IES em agosto/2018}

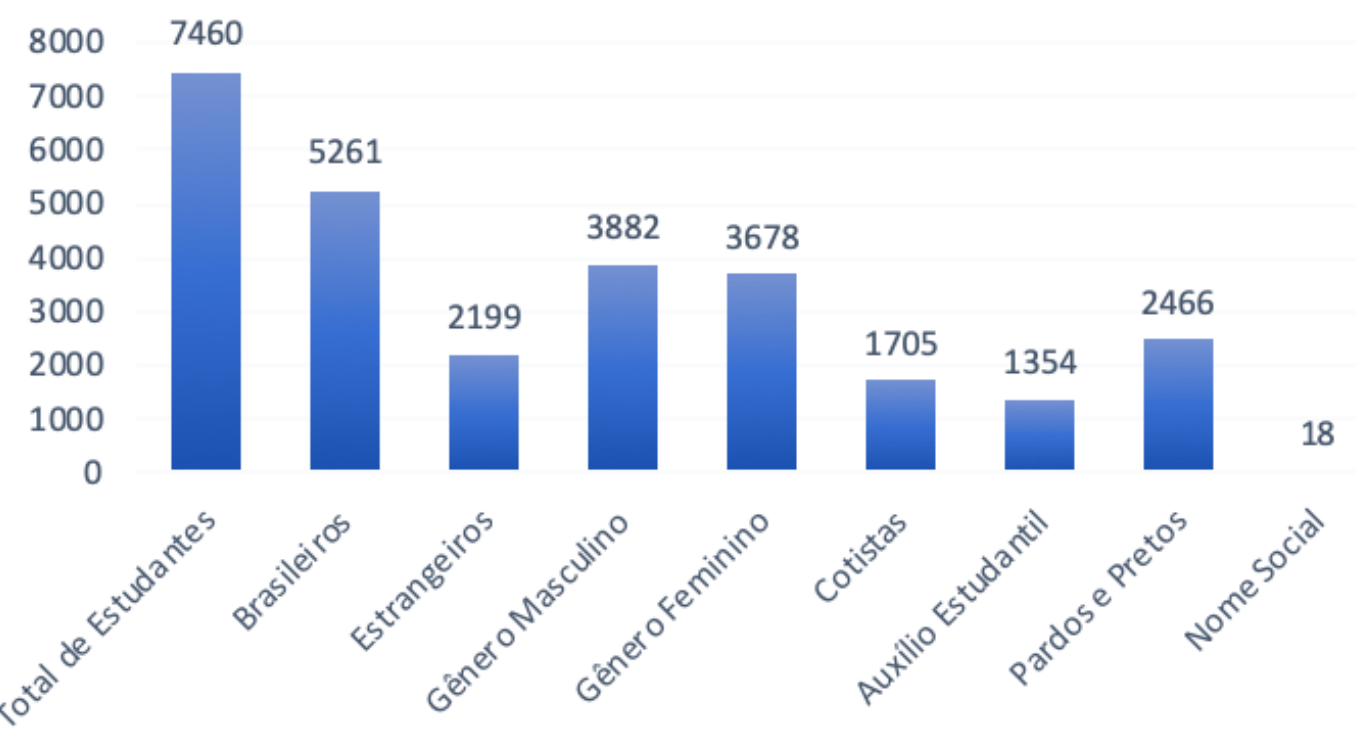

Fonte: Pró-Reitoria de Assuntos Estudantis da IES (Via e-SIC)

Apresentadas as especificidades da instituição escolhida, pretendemos demonstrar, a partir das tomadas fotográficas que compõem sua paisagem, a urgência do tensionamento e da discussão de questões como identidade(s), equidade de gênero, tolerância, ações afirmativas, dentre outras tantas demandas que nos parecem escapar dos muros da universidade, extravasando-se a incontáveis espaços urbanos, midiáticos e virtuais. Para fins de exposição nesse texto, selecionamos um total de seis fotografias, de acordo com a maior frequência do conteúdo discursivo e maior relevância frente às informações recebidas, as quais serão introduzidas e analisadas na sequência.

\section{A paisagem linguística sob análise: nuances de poder e de resistência}

De modo a compreendermos a motivação das intervenções linguísticas 'não-oficiais', as chamadas 'pichações', compondo os espaços urbanos, partimos da assunção de que a paisagem linguística se configura como um espelho da própria sociedade, revelando seus aspectos sociais, econômicos e políticos. Entendemos que pensar a cidade a partir das manifestações visuais e questionamentos de determinados grupos pode levar à ressignificação dos seus espaços enquanto palco de resistência contra as formas de sujeição, uma vez que as "imagens sempre operam simultaneamente mostrando e escondendo coisas." (GOMES, 2013, p. 31). Ao 
V. 9 (2)

$396-414$

maio-ago

2019

imprimir sua manifestação em local não autorizado, o autor está afirmando, além de sua existência, sua não assimilação pelos mecanismos de poder que regem quem tem o direito ao espaço público. Dessa forma, pautamo-nos nos postulados de Foucault (1979; 1995; 2010; 2014) ao percorrer como se dão as relações que levam os sujeitos a atuarem sobre outros sujeitos, através de mecanismos que os coagem, controlam e disciplinam. Ao contrário de um poder que se estabelece única e verticalmente a partir do Estado, para o autor, o poder atravessa toda a estrutura da sociedade, sendo cada sujeito um lugar de passagem desse poder, conforme Foucault (1979):

O poder deve ser analisado como algo que circula, ou melhor, como algo que só funciona em cadeia. Nunca está localizado aqui ou ali, nunca está nas mãos de alguns, nunca é apropriado como uma riqueza ou um bem. O poder funciona e se exerce em rede. Nas suas malhas os indivíduos não só circulam mas estão sempre em posição de exercer este poder e de sofrer sua ação; nunca são o alvo inerte ou consentido do poder, são sempre centros de transmissão. Em outros termos, o poder não se aplica aos indivíduos, passa por eles. (FOUCAULT, 1979, p. 183)

Desse modo, não só os aparatos do Estado estabelecem normativas que controlam o que pode ser feito, o que deve ser visto, como também os próprios indivíduos, apropriando-se de premissas estabelecidas por determinado grupo dominante que regula o discurso do que lhe convém. A essa forma de agência reguladora disseminada, Foucault dá o nome de poder disciplinar. Para ele, esse poder disciplinar trará um discurso que "[...] será o da regra; não o da regra jurídica derivada da soberania, mas o da regra natural, isto é, da norma", estabelecida a partir dos parâmetros hegemônicos do que se pode ou se deve (FOUCAULT 2010, p. 33). Dessa maneira se redefine e se diferencia o belo do feio, a arte da banalidade, o bom do mau, o valoroso do irrelevante, afetando assim a visibilidade e a percepção sobre diversos elementos dispostos no espaço urbano os quais perfazem a PL, campo de estudo ao qual se dedica essa pesquisa.

Como resultado dessas dicotomias, exerce-se nas tramas sociais a necessidade de 'normalização' (FOUCAULT, 2010) que, inevitavelmente será contestada a partir de insurgentes manifestações de resistência, lembrando que, para Foucault (2014), "onde há poder, há resistência". Para efeito dessa análise em PL, apresentamos a seguir as intervenções as quais entendemos como manifestações de resistência expressas no ambiente sociolinguístico dessa pesquisa. Essas intervenções tangem questões de diversidade linguística, questões de gênero e cor e questões de poder. 
Tomamos primeiramente como objeto de análise as intervenções multilíngues, visto ser a instituição aqui escolhida composta por quase $30 \%$ de estudantes estrangeiros advindos de diversos países da América Latina e Caribe, segundo dados apresentados anteriormente no Gráfico 1. Conforme Berger (2015), a presença ou ausência de determinadas línguas em um dado espaço circunscrevese a determinadas práticas e estratégias denominadas "gestão de línguas", definida como:

(...) a administração da presença e do lugar das línguas em dada sociedade ou espaço social por meio de estratégias e/ou práticas adotadas por sujeitos e/ou grupos que exercem algum nível de autoridade (poder), intervindo nas relações dos falantes com as línguas. Tais estratégias e/ou práticas são/podem ser adotadas, por exemplo, como forma de lidar com situações não previstas ou críticas em dado contexto de coexistência de línguas. Para tanto, os participantes/agentes lançam mão da autoridade que exercem em dado domínio para conduzi-las. (BERGER, 2015, p. 58)

Desse modo, compreendem-se as intervenções em línguas diferentes do português como uma forma de manifestar a existência de diferentes grupos naquele meio, como uma maneira de cravar sua identidade linguística em um espaço de resistência plural. Percebe-se assim a necessidade de visibilizar os grupos por trás dessas mensagens. Nesse sentido, concordamos com Gomes (2013) no que se refere às interferências do que se observa na paisagem para uma compreensão mais ampla do contexto social. Segundo o geógrafo:

O atributo da visibilidade é, portanto, central na vida social moderna e se ativa e se exerce pela existência dos diferentes espaços públicos. Dessa maneira, as dinâmicas que afetam a visibilidade, aquilo que se exibe, o público que observa, tudo isso deve ser reunido na compreensão da vida social. (GOMES, 2013, p.23)

Apresentamos na sequência dois registros fotográficos que se caracterizam como marcadores da existência e de tentativa de visibilidade de diferentes grupos de fala. 
v. 9 (2)

396-414

maio-ago

2019
Figura 1 - Intervenção em parede interna

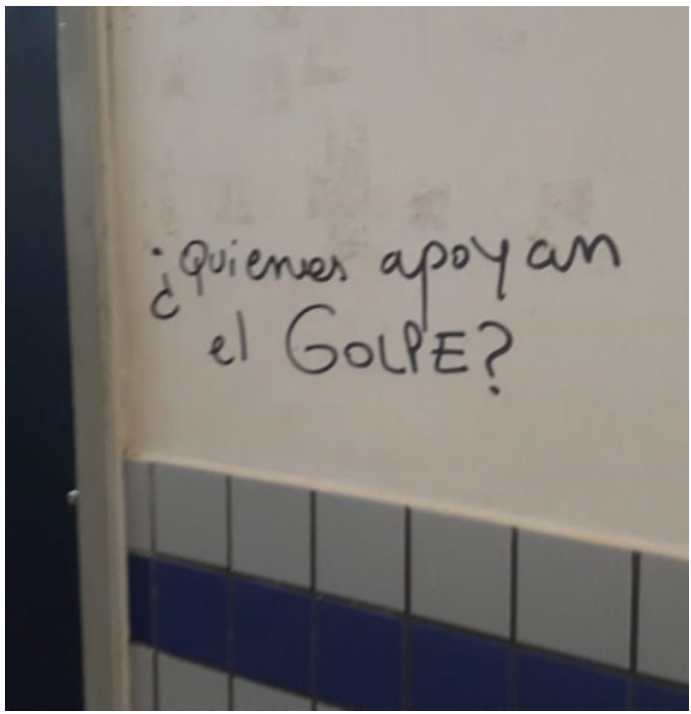

Fonte: Foto de arquivo pessoal das autoras.
Figura 2 - Intervenção em parede interna

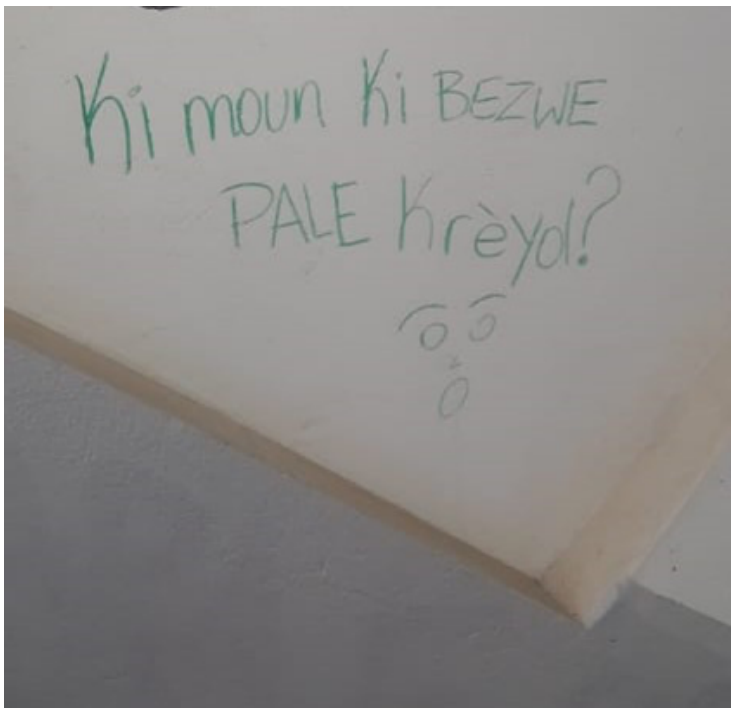

Fonte: Foto de arquivo pessoal das autoras.

Como podemos observar na Figura 1, há a inscrição em língua espanhola "¿Quines apoyan el golpe?” (Quem apoia o golpe?), fazendo referência à situação política brasileira. Já a Figura 2 nos apresenta a inscrição "Ki moun ki bezwe pale krèyd?", cuja tradução da língua crioula haitiana para o português significa "Quem precisa falar de forma cruel?", marcando também a forte presença haitiana nos corredores da universidade que, embora tenha em sua concepção a ideia da diversidade linguísticocultural, tem o português como idioma institucional majoritário.

Uma vez que ambas as intervenções caracterizam-se por perguntas, verificamos a demanda por interlocução com o mundo exterior, uma espécie de estímulo ao diálogo, à obtenção de respostas, em que provocações são lançadas de modo a se refletirem, seja para afirmar a existência dos autores, tal qual suas identidades linguísticas, seja para afirmar seu escape à "normalização", nos termos de Foucault (2010). De acordo com o autor, essa 'normalização' se estabelece pela forma de práticas do que pode ou do que não pode ser realizado pelos sujeitos, sendo então as intervenções e pichações nos espaços públicos uma forma de resistência inevitável, de subversão da forma de poder exercida pela regulamentação, uma vez que, para Foucault (1995):

Não há relação de poder sem resistência, sem escapatória ou fuga, sem inversão eventual; toda relação de poder implica. então, pelo menos de modo virtual, uma estratégia de luta, sem que para tanto venham a se superpor, a perder sua especificidade e finalmente a se confundir. (FOUCAULT, 1995, p. 248) 
A partir das intervenções expostas, verifica-se a heterogeneidade linguística que compõe a paisagem em análise, bem como a busca desses diferentes grupos linguísticos em se fazerem partícipes daquele ambiente, demonstrando, através da prática dessas intervenções, que estão atrelados àquele espaço de socialização e àquele momento histórico. Dentre o total das 53 fotografias tiradas das intervenções linguísticas do campus universitário, chamou-nos atenção o grande número de intervenções que se referiam à representatividade da presença de estudantes pretos e pardos no corpo discente. Da mesma forma, muitas dessas intervenções associavam-se também às questões de violência e preconceito sofridos por esses e essas estudantes.

Deacordocomdadosjáexpressosnessapesquisa, disponibilizados pela instituição de ensino através do serviço eletrônico de informação ao cidadão (e-SIC), estudantes pardos e pretos conformam 33\% do total de estudantes da universidade em questão. Esse dado é expressivamente distante da realidade populacional brasileira que, de acordo com pesquisa realizada pelo IBGE, é formada por $54,9 \%$ de pessoas pretas e pardas ${ }^{8}$. A não consonância da representatividade numérica desses estudantes na universidade em relação à sua representatividade populacional brasileira parece motivar a expressiva parte das intervenções captadas por meio dessa pesquisa. Apresentamos, na sequência, dois registros em que é possível verificar essa forma de intervenção.

${ }^{8}$ Matéria publicada pela agência de notícias do IBGE (Instituto Brasileiro de Geografia Estatística) em 24 de novembro de 2017. 
V. 9 (2)

$396-414$ maio-ago 2019
Figura 3 - Intervenção em parede externa

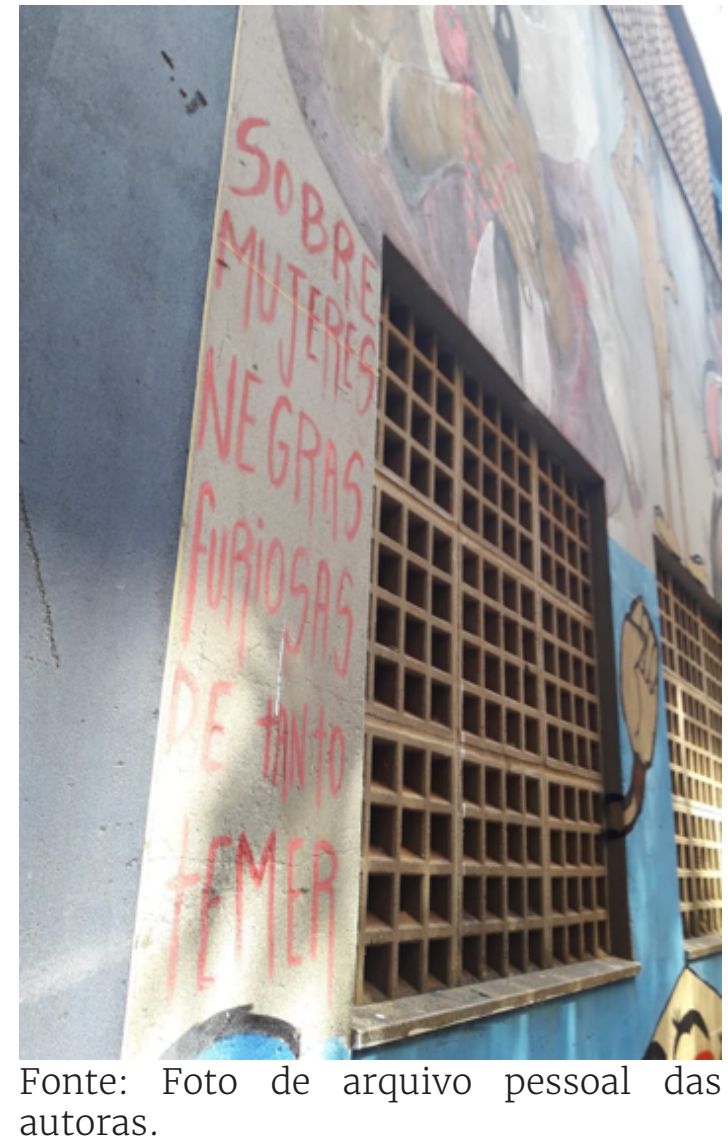

Figura 3 - Intervenção em parede interna

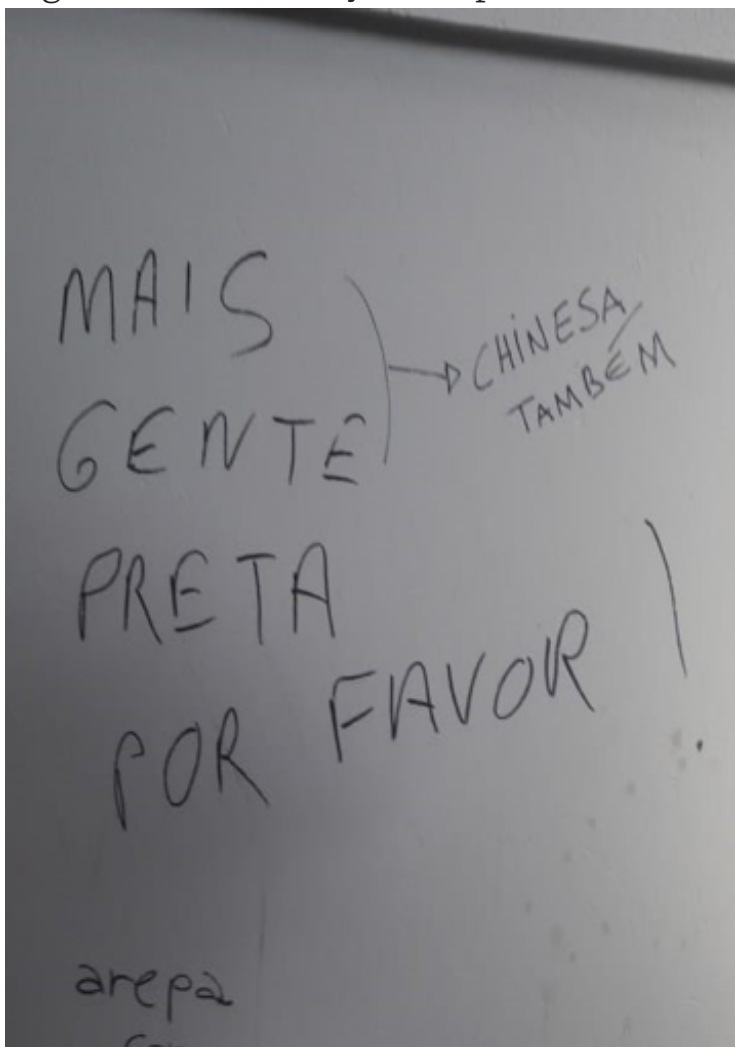

Fonte: Foto de arquivo pessoal das autoras.

Observa-se na Figura 3, uma fotografia extraída da parede externa do campus universitário trazendo a inscrição "Sobre mujeres negras furiosas de tanto temer". Percebe-se que houve o esforço de tornar esse clamor contra a violência sofrida por essas mulheres muito visível, sendo utilizada a tinta vermelha que, além de se destacar pela tonalidade vibrante, também pode representar o sangue derramado pelas mulheres negras que foram vítimas da violência. Ainda, outra possibilidade de interpretação dessa inscrição pode se referir ao plano político, uma vez que manifestações em oposição ao presidente governante na época foram percebidas na paisagem.

Já na segunda intervenção (Figura 4), pode-se ler o pedido por "Mais gente preta por favor", seguida da réplica "Chinesa também", demonstrando o descontentamento dos autores frenteà representatividade de pessoas negras (e também chinesas) naquele ambiente universitário. Concordando com o pressuposto de que a PL se manifesta como um espelho da sociedade, inferimos que, a partir dessas intervenções recortadas de apenas um espaço urbano, temos a própria representação em nível macro da sociedade, ao lembrarmos que a necessidade de maior representatividade de pessoas negras nas esferas sociais e políticas é uma demanda ainda não satisfatoriamente atingida. 
Quanto a essa relação que se estabelece entre micro e macro esferas a partir da linguagem, Severo (2013) assinala que

O estudo local da dinâmica do poder em relação às línguas pode tornar-se particularmente revelador quando confrontado aos estudos macro, que focalizam as instâncias regulamentadoras estatais. Neste confronto, como se dá a relação entre o micro e o macro? Não se trata, nesse caso, de considerar o micro como efeito do macro, mas de averiguar como ambos se relacionam produzindo efeitos mútuos. (SEVERO, 2013, p. 459)

Ainda nesse sentido, ao demonstrar os estudos realizados em relação aos excluídos (outsiders) de uma pequena comunidade em relação às manifestações de poder, Elias (2000) ressalta que a repetição e regularidade de fenômenos observados no microcosmo dessa comunidade preconizava possibilidades de análise para a compreensão de estudos em nível macrossociológico.

Muitas vezes visto como fruto de um comportamento transgressor, a intervenção não autorizada nos espaços urbanos tende a ser apagada pelas autoridades municipais, invisibilizando esses atos de resistência e impondo as normas que tencionam uniformizar o comportamento social, agindo nessa trama de poder que institui o que pode e o que não pode ser visto. Nesse processo, além da proibição da expressão individual ou coletiva incutida naquela forma linguística, há também a negação da possibilidade de promoção de sentido do público que transita nos espaços e percebe as intervenções. Sobre a importância dessa relação do público observador com a intervenção, Gomes (2013, p. 79) ressalta que "há um distanciamento que se coloca entre o observador e aquilo que é observado capaz de gerar um ponto de vista diverso daquele que a cotidianidade e convivência ordinária nos imprimem".

Nesse sentido, muitas fotografias de intervenções manifestadas a partir do direito de existir, de se expressar e de se representar fizeram parte da coletânea de fotos extraídas desse espaço público universitário. Apresentam-se, a seguir, dois desses registros. 
V. 9 (2)

$396-414$

maio-ago 2019
Figura 5 - Intervenção em parede interna

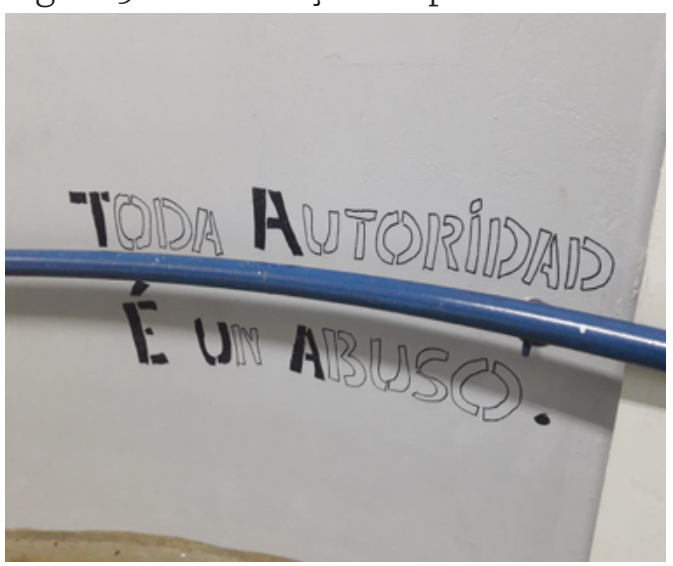

Fonte: Foto de arquivo pessoal das autoras.
Figura 6 - Intervenção em parede interna

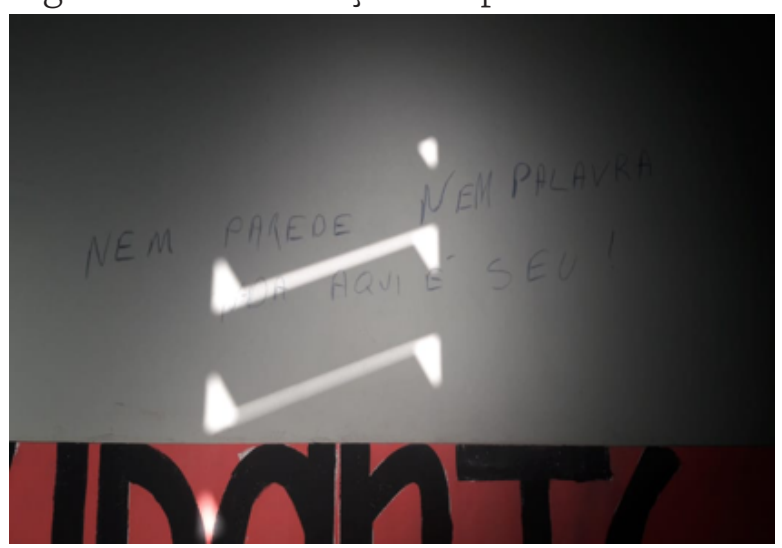

Fonte: Foto de arquivo pessoal das autoras.

De acordo com o conteúdo da Figura 5, coletada no interior do campus junto ao corrimão de uma escada, observamos pela legenda "toda autoridad é un abuso", a irredutível tensão gerada entre os órgãos reguladores e os sujeitos dominados, impelidos por um sistema de coação. Já na Figura 6, observamos a inscrição "nem parede nem palavra aqui nada é seu", afirmando a possível falta de direito tanto à expressão quanto à apropriação daquele espaço público como pertencente aos grupos que ali transitam. Assim, a noção de propriedade que subjaz a essa intervenção explicita a subjugação sofrida por esses autores, que alegam não ter espaço nem voz nessa sociedade marginalizadora.

Diante dessas exposições, consideramos que o espaço público pode se caracterizar como lugar de expressão das subjetividades de variados grupos e que a análise da PL, por sua vez, ao levar em consideração as condições de produção e seus agentes, tem muito a acrescentar na compreensão da construção desses espaços de convívio e expressão.

\section{Considerações finais}

De acordo com Spolsky (2009), muitos estudos em Paisagem Linguística têm sido realizados no que se refere à presença ou ausência de línguas no espaço, porém ainda pouco se analisa sobre as condições de produção dos sinais linguísticos nos espaços urbanos.

Esse estudo, fundamentado no campo da PL, buscou compreender como as intervenções linguísticas que formam parte da paisagem de um campus universitário multicultural podem representar expressões de resistência e de não assimilação dos mecanismos de poder que regem o que pode e o que não pode ser exibido no espaço público. 
A análise dessas intervenções a partir de fotografias extraídas desse ambiente revelou ser uma ferramenta profícua para a percepção de questões sociais, políticas e econômicas que permeiam aquela comunidade acadêmica, que tem, nas batalhas linguísticas travadas nas paredes, seu grito por visibilidade e representação.

Acreditamos, para efeito desse estudo, que as manifestações insurgentes aqui apresentadas podem nos ajudar a entender o uso do espaço público como lugar de expressão das subjetividades dos grupos, levando-nos, a partir da apreensão dessas subjetividades, a compreender questões controversas da sociedade.

Entendemos que, como encaminhamentos para pesquisas futuras, haja a necessidade de que o olhar sobre as motivações e circunstâncias de produção das intervenções linguísticas seja levado a outros espaços da cidade, atravessando os muros da universidade, propiciando assim uma análise mais ampliada das questões sociais que subjazem a Paisagem Linguística.

\section{Referências}

BEN-RAFAEL, Eliezer; SHOHAMY, Elana; AMARA, Muhammad Hasan; TRUMPER-HECHT, Nira. "Linguistic Landscape as Symbolic Construction of the Public Space: The case of Israel". In: GORTER, Durk (Org.) Linguistic Landscape: A New Approach to Multilingualism. Toronto: Multilingual Matters LTD, 2006. p. 7-30.

BERGER, I. R. Gestão do multi/plurilinguismo em escolas brasileiras na fronteira Brasil - Paraguai: um olhar a partir do Observatório da Educação na Fronteira. 2015. 300 f. Tese (Doutorado) - Universidade Federal de Santa Catarina, Florianópolis, 2015.

BERGER, I. R. Territórios linguísticos em escolas na fronteira: reflexões sob a ótica interdisciplinar da Política Linguística. In: SILVA, R. C. M.; MORAES, D. R. S. Interdisciplinaridade e saberes: interlocuções entre fronteiras. Cascavel, P: Edunioeste, 2016.

BERGER, I. R.; ELSENBACH, L. R. J. Gestão do multilinguismo no espaço visual público em Foz do Iguaçu: um estudo sobre a visibilidade da diversidade linguística. Entrepalavras, Fortaleza, v. 7, p. 433-456, ago./dez. 2017.

BRASIL. IBGE. População chega a 205,5 milhões, com menos brancos e mais pardos e pretos. IBGE, 2017. Disponível em: < https://agenciadenoticias.ibge. gov.br/agencia-noticias/2012-agencia-de-noticias/noticias/18282-pnad-cmoradores > Acesso em: 17 set 2018.

FOUCAULT, M. Microfísica do poder. $21^{\mathrm{a}}$ ed. Rio de Janeiro: Graal, 1979. 
V. $9(2)$

$396-414$ maio-ago 2019

414

e da hermenêutica. Tradução V. P. Carrero. Rio de Janeiro: Forense Universitária, 1995. p. 231-249.

FOUCAULT, $M$. Em defesa da sociedade. Curso no Collège de France (1975 - 1976). Tradução de Maria Ermantina Galvão - 2a ed. São Paulo: WMF Martins Fontes, 2010.

FOUCAULT, M. História da Sexualidade 1: a vontade de saber. Tradução Maria Thereza da Costa Albuquerque e J. A. Guilhon Albuquerque. 1 ed. São Paulo, Paz e Terra, 2014.

GIL, Antônio Carlos. Métodos e Técnicas de Pesquisa Social. 6 ed. São Paulo: Editora Atlas, 2011.

GOMES, P. C. C. O lugar do olhar: elementos para uma Geografia da Visibilidade. Rio de Janeiro: Bertrand Brasil, 2013.

GORTER, D. Linguistic Landscape: A New Approach to Multilingualism. Toronto: Multilingual Matters LTD, 2006.

LANDRY, R.; BOURHIS, R. Y. Linguistic Landscape and Ethnolinguistic Vitality: An Empirical Study. Journal of Language and Social Psychology. March 1997 vol. 16 no. 1 p. 23-49.

MALINOWSKI, D. Authorship in linguistic landscape: A multimodal performative view. In SHOHAMY, E.; GORTER, D. Linguistic Landscape: Expanding the scenery. New York: Routledge, 2009.

RAYNAUT, C. Interdisciplinaridade: mundo contemporâneo, complexidade e desafios à produção e à aplicação de conhecimento. In: PHILIPPI JR, A.; SILVA NETO, A.J. (Ed.) Interdisciplinaridade em ciência, tecnologia e inovação. Barueri, SP. Ed. Manole, 2011. P.69-105.

SEVERO, C. G. Política (s) Linguística (s) e questões de poder. Alfa Revista de Linguística. UNESP, 2013.

SHOHAMY, E. Language in public space. In: SHOHAMY, E. Language Policy: hidden agendas and new approaches. New York: Routledge, 2006.

SHOHAMY, E; GORTER, D. Linguistic Landscape: Expanding the scenery. New York: Routledge, 2009.

SILVA, I.; PIRES-SANTOS, M.E.; JUNG, N. M. Multilinguismo e política linguística: análise de uma paisagem linguística transfronteiriça. Domínios da Linguagem. vol. 10 n.4 | out. /dez. 2016, p. 1257-1277.

SOARES, M.S. "Só barulho do spray foskando algum tom": Os grafismos urbanos na paisagem sociolinguistica da cidade de Juíz de Fora/MG. 2018. 213 f. Tese (Doutorado em Linguística) - Universidade Federal de Juíz de Fora, 2018.

SPOLSKY, B. Language Management. UK: Cambridge University. Press, 2009. 